\title{
Exploring the acceptability of human
}

\section{papillomavirus self-sampling among Muslim immigrant women}

This article was published in the following Dove Press journal:

Cancer Management and Research

19 July 2017

Number of times this article has been viewed

\section{Aisha K Lofters ${ }^{1-4}$ \\ Mandana Vahabi $i^{5,6}$ \\ Mitra Fardad ${ }^{7}$ \\ Afrah Raza ${ }^{8}$}

'Centre for Urban Health Solutions, Li Ka Shing Knowledge Institute, St. Michael's Hospital, ${ }^{2}$ Department of Family and Community Medicine, University of Toronto, ${ }^{3}$ Department of Family and Community Medicine, St. Michael's Hospital, ${ }^{4}$ Institute for Clinical Evaluative Sciences, ${ }^{5}$ Faculty of Community Services, Daphne Cockwell School of Nursing, ${ }^{6}$ Graduate Program in Immigration and Settlement Studies, Ryerson University, ${ }^{7} \mathrm{Faculty}$ of Community Service, Daphne Cockwell School of Nursing, Ryerson University, Toronto, ON, Canada; ${ }^{8}$ University of Michigan Medical School, Ann Arbor, MI, USA

Correspondence: Aisha K Lofters Centre for Urban Health Solutions, Li Ka Shing Knowledge Institute, St. Michael's Hospital, 30 Bond Street, Toronto, ON M5B IW8, Canada

Tel + I 4168677428

Fax + I 4I68677498

Email aisha.lofters@utoronto.ca
Background: With appropriate screening (ie, the Papanicolaou [Pap] test), cervical cancer is highly preventable, and high-income countries, including Canada, have observed significant decreases in cervical cancer mortality. However, certain subgroups, including immigrants from countries with large Muslim populations, experience disparities in cervical cancer screening. Little is known about the acceptability of human papillomavirus (HPV) self-sampling as a screening strategy among Muslim immigrant women in Canada. This study assessed cervical cancer screening practices, knowledge and attitudes, and acceptability of HPV self-sampling among Muslim immigrant women.

Methods: A convenience sample of 30 women was recruited over a 3-month period (JuneAugust 2015) in the Greater Toronto Area. All women were between 21 and 69 years old, foreign-born, and self-identified as Muslim, and had good knowledge of English. Data were collected through a self-completed questionnaire.

Results: More than half of the participants falsely indicated that Pap tests may cause cervical infection, and $46.7 \%$ indicated that the test is an intrusion on privacy. The majority of women reported that they would be willing to try HPV self-sampling, and more than half would prefer this method to provider-administered sampling methods. Barriers to self-sampling included confidence in the ability to perform the test and perceived cost, and facilitators included convenience and privacy being preserved.

Conclusion: The results demonstrate that HPV self-sampling may provide a favorable alternative model of care to the traditional provider-administered Pap testing. These findings add important information to the literature related to promoting cancer screening among women who are under or never screened for cervical cancer.

Keywords: cancer screening, HPV, self-sampling, immigrant health

\section{Background}

Cervical cancer, one of the most common causes of cancer-related mortality and morbidity for women worldwide, is highly preventable with screening using the Papanicolaou (Pap) test. ${ }^{1-4}$ Population-based screening has led to significant decreases in cervical cancer incidence and mortality in high-income countries such as Canada; however, certain subgroups of Canadian women, including immigrant women, are less likely to get screened for cervical cancer. ${ }^{5-9}$ Studies have demonstrated that the lowest screening rates are for Ontario immigrant women from South Asia and the Middle East and North Africa. ${ }^{6-8}$ Many of these women may be Muslim. One of the fastest growing immigrant groups in Canada is people of Muslim faith and culture, with a growth rate of $82 \%$ over the past decade from $\sim 579,000$ in 2001 to $>1$ million 
in 2011. ${ }^{9}$ The Muslim population in Canada is expected to triple over the next 20 years, with the majority coming from South Asian and Middle Eastern countries. Approximately $73 \%$ of Canadian Muslims live in Ontario, Canada's most populous province with $\sim 13$ million people, and home to Toronto, Canada's most populous and diverse city. ${ }^{9}$

Virtually, all cases of cervical cancer are caused by the pervasive human papillomavirus (HPV). ${ }^{10}$ Self-sampling for HPV may be a viable method of screening for the virus that causes cervical cancer, either by cotesting with the Pap test or as a primary screening test used to triage women for subsequent Pap testing. ${ }^{10-14}$ Self-sampling for HPV has been shown to have validity compared to clinician-collected cervical samples, as well as to have high acceptance among women. ${ }^{15-22}$ Self-sampling for HPV has the potential to address many of the screening barriers identified in the literature and to promote screening uptake among vulnerable groups. However, little is known about the acceptability of and preference for this evidence-based strategy among immigrant women who are Muslim.

To address this gap, we conducted a community-based sequential mixed methods' study to explore cervical cancer screening knowledge and attitudes and the acceptability of HPV self-sampling among Muslim immigrant women in the Greater Toronto Area (GTA), where many Muslim immigrants settle. Our study was guided by the Population Health Promotion Framework ${ }^{23,24}$ and utilized a socioenvironmental approach to address health disparities, which is grounded in the principles of social justice and equity. ${ }^{25-27}$

\section{Methods}

This study consisted of a detailed questionnaire followed by focus groups to explore Muslim immigrant women's knowledge, attitudes about cervical cancer and screening, and the cultural relevance, appropriateness, and acceptability of self-sampling for HPV. This article focuses on the results from the survey component of the study. The results of the focus groups are published elsewhere. ${ }^{28}$

\section{Sample}

Through intensive outreach with the assistance of community partners (ie, local mosques) and snowball sampling, a convenience sample of 30 women was recruited by our communitybased research assistants (RAs). Importantly, our RAs were women who self-identified as Muslim and had preexisting relationships with the local Muslim community. The target population was women who 1) resided in the GTA, 2) were aged 21-69 years in line with provincial cervical screening guidelines, ${ }^{29} 3$ ) were foreign-born, 4) were able to converse in English, and 5) were self-identified as Muslim.

\section{Data collection and measures}

All data were collected by our community-based RAs between May and August 2015. The RAs assessed the eligibility of participants, obtained consent, and set a convenient time and place to administer the self-completed questionnaires. Participants completed the questionnaire depending on their preference, either in a quiet room at designated partner mosques or at the participant or RA's home. The questionnaire explored women's sociodemographic characteristics, cervical cancer screening practices, barriers to screening, knowledge and attitudes related to cervical cancer, ${ }^{30,31}$ and their preference for HPV self-sampling vs provider-administered sampling. Self-sampling for HPV was defined on the questionnaire as a "self-administered screen for cervical cancer where you would be able to collect your own sample in the privacy of your home". Open-ended questions were included to elicit participants' opinions about the HPV self-sampling and their preferred methods of cervical screening. The open-ended questions were as follows:

What do you think about self-sampling screening for cervical cancer where you would be able to collect your own sample in the privacy of your home? (please explain)

Is this something you would want to try? (please explain) and

Which of the following cervical cancer screening sampling methods would you prefer 1) Self-sampling (when you collect the sample) or; 2) Provider-administered- (when a medically trained person collects the sample). Please explain your selection.

\section{Analysis}

Quantitative data were analyzed using SPSS version 23. Descriptive statistics summarized participants' sociodemographic characteristics and their knowledge. Comments in response to open-ended questions were content analyzed using constant comparison analysis. We systematically read the text, highlighted important passages and words, and organized these into relevant themes and categories. Integrity in coding and data interpretation was maintained through strategies of credibility (ie, peer debriefing).

For knowledge of and attitudes toward cervical cancer, preexisting tools were adapted. ${ }^{30,31}$ Responses to the knowledge items included "true", "false", and "do not know". To measure women's cervical cancer screening attitudes, we 
grouped the questions into the following four categories: 1) effectiveness of screening, 2) utilization of screening (conducting Pap tests in the absence of symptoms), 3) quality of equipment (whether instruments used to do Pap tests were of good quality), and 4) barriers that may affect use (whether Pap tests were viewed as expensive, painful, time consuming, and disturbing the privacy of women). Responses were captured on a 5-point Likert scale of "completely disagree", “disagree", "no idea", "agree", and "completely agree".

\section{Ethical approval}

All procedures performed in this study were in accordance with the ethical standards of the institutional and/or national research committee and with the Declaration of Helsinki 1964 and its later amendments or comparable ethical standards. The study protocol received ethical approval from the Human Subjects Review Committee at Ryerson University. All participants provided written consent to participate.

\section{Results}

\section{Sociodemographic characteristics}

Table 1 presents the sociodemographic characteristics of the 30 study participants. Detailed demographics have been published elsewhere. ${ }^{28}$ Half were from West Asia (ie, Iran)

Table I Sociodemographic characteristics of participants

\begin{tabular}{|c|c|c|}
\hline Characteristics & $\mathbf{n}$ & $\%$ \\
\hline \multicolumn{3}{|l|}{ Age group (years) } \\
\hline $21-39$ & 14 & 45.7 \\
\hline $40-69$ & 16 & 53.3 \\
\hline \multicolumn{3}{|l|}{ Current relationship status } \\
\hline Married/common law & 24 & 80.0 \\
\hline Others & 6 & 20.0 \\
\hline \multicolumn{3}{|l|}{ Rating of English reading, writing, and speaking abilities } \\
\hline Excellent & 10 & 33.3 \\
\hline Good & 15 & 50.0 \\
\hline Fair & 5 & 16.7 \\
\hline \multicolumn{3}{|l|}{ Highest level of education } \\
\hline High school ( 12 grades) or equivalent & 3 & 10.0 \\
\hline $\begin{array}{l}\text { College (eg, diploma) or university (eg, BA } \\
\text { and BSc) }\end{array}$ & 16 & 53.3 \\
\hline $\begin{array}{l}\text { Postgraduation (eg, MA and PhD), some or } \\
\text { completed }\end{array}$ & 11 & 36.7 \\
\hline \multicolumn{3}{|l|}{ Current employment status in Canada } \\
\hline Full-time employed (minimum of 35 hours/week) & 6 & 20.0 \\
\hline Others & 7 & 23.3 \\
\hline Part-time employed & 7 & 23.3 \\
\hline Unemployed & 10 & 33.3 \\
\hline \multicolumn{3}{|l|}{$\begin{array}{l}\text { Approximate household annual income from all sources } \\
\text { after taxes }\end{array}$} \\
\hline$\leq \mathrm{CAD} \$ 75,000$ & 12 & 40.0 \\
\hline$>C A D \$ 75,000$ & 4 & 13.3 \\
\hline Do not know/do not want to answer & 14 & 46.7 \\
\hline
\end{tabular}

and the rest from South Asia (ie, Pakistan and India). The mean age was 39.7 years (standard deviation 11.4 years). The majority (60\%) of women had lived in Canada for $\geq 10$ years. Participants were relatively well educated $(90 \%$ had some postsecondary education), but one-third were unemployed.

\section{Cervical cancer screening practices and barriers to screening}

More than three-quarters (78\%) of the women reported ever having a Pap test, and most of those (87\%) reported having the test within the past $1-3$ years, reflecting that more than a third of the participants were either under or never screened based on the provincial cervical cancer screening guidelines, which recommend a Pap test at least once every 3 years. ${ }^{41}$ Reasons provided by those who had never had the test included: not thinking it was necessary, their doctor did not think it was necessary, concern about cost, not knowing where to go, and being uninformed.

\section{HPV self-sampling}

Participants were asked in both closed and open-ended questions how they felt about HPV self-sampling. Two-thirds $(67 \%)$ indicated that self-sampling was something they would be willing to try, while $10 \%$ indicated "no" or "not sure", and $23 \%$ did not answer this question. Notably, $93 \%$ of women aged 21-39 years indicated that they would use HPV selfsampling compared to $44 \%$ of older women (40-61 years) ( $X^{2}=8.10, P$-value 0.007 ). Similarly, $87 \%$ of women from Iran indicated a willingness to try HPV self-sampling compared to only $47 \%$ of women from Pakistan/India. Reasons provided by those willing to try HPV self-sampling were related mainly to issues of privacy and convenience. Several women felt that this was a good solution especially when women may be shy, modest, or busy with other life demands. One participant wrote: "I think this way is better than [the] old way because some women like me are very shy and they prefer to do it themselves if know how". Some women expressed feeling shy even when having female physicians. Women felt that this method of testing for HPV would be easy, manageable, and safe. They also felt that this method would be convenient as it would save them time booking an appointment to see their physician, traveling to their physician's office, and waiting at the office to see their physician. Similarly, some pointed out the financial gain for not needing to taking time off work or paying for a babysitter to visit their primary care provider.

Several women reported that it would be important to have proper instructions on how to carry out the test. Some indicated that this strategy would encourage women to do 
it more regularly, the importance of which was reflected in one participant's statement: "Yes, for sure. It would be more convenient and more comfort[able]. So I can do it more often and more regularly".

Among those who did not want to do the test, the reasons provided were mainly due to the lack of knowledge and the lack of confidence in their ability to conduct the test appropriately. They trusted providers more and felt that the test done by trained physicians would be more accurate, particularly if a female provider was available. Some were also concerned about the cost of HPV self-sampling as they argued that it is not currently endorsed by a government body and they would have to shoulder the cost.

When we asked participants to indicate their preferred method of cervical screening (HPV self-sampling vs provider-administered sampling), slightly more than half (56\%) selected the self-sampling method, while $44 \%$ preferred provider-administered cervical screening. The majority of women from Iran preferred HPV self-sampling compared to those from Pakistan/India (86 vs 23\%) $\left(X^{2}=10.71, P\right.$-value $\left.=0.002\right)$. Reasons provided by those who preferred self-sampling were similar to what was presented above and related mainly to the convenience and privacy of the test. The following quote from a participant reflects these sentiments: "In my opinion the self-sampling method is easy for me to do it myself and it will save me time and improves my health". Similarly, reasons for those who preferred provider-administered sampling were similar to those presented above. This is clearly reflected in the following statement: "the sample taken will be by a professional who knows his job vs. myself who is unable to get the proper picture of what and where I should collect the sample from".

\section{Cervical cancer knowledge}

Table 2 presents the results of the knowledge statements for participants. Although knowledge was generally high, more than half of the women (54\%) falsely indicated that Pap tests may cause cervical infection, and many did not know that Pap tests can be performed during pregnancy. Less than half of the women knew that screening should start at 21 years or later if sexually active.

\section{Attitudes toward cervical cancer screening}

Table 3 shows responses related to participants' attitudes toward different aspects of cervical cancer screening. Although 57\% completely disagreed or disagreed with the statement that the Pap test was expensive (cervical screening is universally covered for landed immigrants and Canadian citizens), 43\% did not know. Similarly, 30\% of women did not disagree that they preferred to do Pap tests only when experiencing cancer.

For the statements related to the effectiveness of cervical screening, the majority of women believed that the Pap test was effective. For attitudes related to the utilization of screening, although the majority believed that Pap tests should be done even in the absence of symptoms, many women were unsure about the quality of screening equipment.

\section{Discussion}

In this first component of an exploratory mixed methods' study, we surveyed 30 self-identified Muslim immigrant women on their knowledge and attitudes about cervical cancer, screening, and HPV self-sampling. The majority of women (2/3) reported that they would be willing to try HPV self-sampling, and a small majority (56\%) indicated that they

Table 2 Participants' knowledge about cervical cancer and screening

\begin{tabular}{|c|c|c|c|c|c|c|}
\hline \multirow[t]{2}{*}{ Knowledge statements } & \multicolumn{2}{|c|}{ True } & \multicolumn{2}{|c|}{ False } & \multicolumn{2}{|c|}{ Do not know } \\
\hline & $\mathbf{n}$ & $\%$ & $\mathbf{n}$ & $\%$ & $\mathbf{n}$ & $\%$ \\
\hline I. Cervical cancer is preventable & $2 I^{a}$ & 70.0 & I & 3.3 & 8 & 26.7 \\
\hline 2. Cervical cancer is curable & $19^{a}$ & 63.3 & 4 & 13.3 & 7 & 23.3 \\
\hline 3. Cervical cancer may be without signs or symptoms in early stages & $24^{\mathrm{a}}$ & 80.0 & 0 & 0.0 & 6 & 20.0 \\
\hline $\begin{array}{l}\text { 4. Having a Pap test before there are symptoms of cervical cancer may help detect cervical } \\
\text { cancer earlier }\end{array}$ & $24^{\mathrm{a}}$ & 80.0 & I & 3.3 & 5 & 16.7 \\
\hline 5. The first Pap test should be done at age 21 or later, provided you are sexually active & $13^{\mathrm{a}}$ & 43.3 & 3 & 10.0 & 14 & 46.7 \\
\hline 6. All women should be tested by Pap test at least every 3 years & $23^{a}$ & 76.7 & 2 & 6.7 & 5 & 16.7 \\
\hline 7. The Pap test is recommended only for older women & 0 & 0.0 & $26^{\mathrm{a}}$ & 86.7 & 4 & 13.3 \\
\hline 8. Pap test should be performed only if infection and bleeding were seen & 0 & 0.0 & $27^{\mathrm{a}}$ & 90.0 & 3 & 10.0 \\
\hline 9. Pap tests can be done among pregnant women & $1 \mathrm{I}^{\mathrm{a}}$ & 36.7 & 10 & 33.3 & 9 & 30.0 \\
\hline 10. Pap tests may cause cervical infection & 4 & 13.3 & $16^{\mathrm{a}}$ & 53.3 & 10 & 33.3 \\
\hline
\end{tabular}

Note: ${ }^{\text {aC } C o r r e c t ~ a n s w e r . ~}$

Abbreviation: Pap, Papanicolaou. 
Table 3 Participants' attitudes toward cancer screening

\begin{tabular}{|c|c|c|c|c|c|c|}
\hline \multirow[t]{2}{*}{ Attitudinal statements } & \multicolumn{2}{|c|}{$\begin{array}{l}\text { Completely } \\
\text { disagree/disagree }\end{array}$} & \multicolumn{2}{|c|}{ No idea } & \multicolumn{2}{|c|}{$\begin{array}{l}\text { Completely } \\
\text { agree/agree }\end{array}$} \\
\hline & $\mathbf{n}$ & $\%$ & $n$ & $\%$ & $\mathbf{n}$ & $\%$ \\
\hline I. The Pap test is expensive & 17 & 56.7 & 13 & 43.3 & 0 & 0.0 \\
\hline 2. The Pap test is painful & 17 & 56.7 & 3 & 10.0 & 10 & 33.3 \\
\hline 3. The Pap test is time consuming & 20 & 66.7 & 4 & 13.3 & 6 & 20.0 \\
\hline 4. The Pap test disturbs women's privacy & 14 & 46.7 & 2 & 6.7 & 14 & 46.7 \\
\hline 5. The Pap test is effective & 2 & 6.7 & 6 & 20.0 & 22 & 73.3 \\
\hline 6. The Pap test is not effective & 21 & 70.0 & 6 & 20.0 & 3 & 10.0 \\
\hline 7. Prefer doing Pap only when experiencing cancer & 21 & 70.0 & 4 & 13.3 & 5 & 16.7 \\
\hline 8. The Pap test is not necessary in women with no symptoms & 24 & 80.0 & 5 & 16.7 & I & 3.3 \\
\hline 9. The equipment used to do Pap test is not of good quality & 14 & 46.7 & 14 & 46.7 & 2 & 6.7 \\
\hline
\end{tabular}

Abbreviation: Pap, Papanicolaou.

would prefer this method to current provider-administered sampling methods. Differences were seen based on age and region of origin. Barriers to self-sampling included confidence in the ability to perform the test and perceived cost, and facilitators included convenience and preserved privacy. Women in our study had some level of knowledge about cervical cancer and screening, but the lack of knowledge seemed to drive their attitudes toward screening.

Our study results suggest that HPV self-sampling may be a viable method to promote the uptake of cervical screening among Muslim immigrant women in our setting. Two-thirds of women were willing to use HPV self-sampling at home, and over half preferred this method over the provideradministered method. The reasons provided for the preference for self-sampling related to factors that have been suggested as barriers that prevent under-screened women from participating in cervical screening. Privacy was a main reason offered by many women, who indicated that the method would be appropriate for those who are modest or shy. The ability to conduct the test at a time and place selected by the woman, the advantages of being able to save time and money related to taking time off work, needing child care, traveling to physicians' offices, and waiting in the waiting room were raised as reasons for participants' preferences for HPV self-sampling. Hence, our study supports earlier studies demonstrating that HPV self-sampling has the potential to overcome many of the identified barriers in the literature. ${ }^{15-22}$

Unlike what has been reported in the literature, ${ }^{32-40}$ a high proportion of women (78\%) in our pilot study reported ever having a Pap test. However, this finding should be interpreted with caution as it was based on self-report, which has been shown to not be as reliable and accurate a method as objective measures in determining screening rates due to recall, acquiescence, and social desirability biases. ${ }^{41-43}$ We were not able to validate women's self-reported screening practice against more objective measures. Furthermore, the high rate of self-reported Pap test may be due to the fact that the study participants had relatively high education and had been in Canada for a relatively long time. Many participants were still overdue for screening by self-report.

The barriers identified by those participants who did not have Pap tests, such as not knowing where to go, being uninformed, not thinking it was necessary, and their doctor not providing a recommendation, were similar to what has been reported in previous studies. ${ }^{6,732-40}$ Furthermore, some of our participants identified cost as a barrier for cervical cancer screening, which strongly highlights the need for the education and provision of information regarding the Canadian universal health care system and services available through primary care providers.

The questions related to women's attitudes about cervical cancer and screening revealed some potential barriers that may affect women's participation in screening. A considerable proportion believed that Pap tests are painful, time consuming, and costly, and/or disturb women's privacy. These results suggest a need to educate women about the benefits of regular screening and to provide safe and comfortable ways in which they can easily access screening services and also further support HPV self-sampling as a viable screening alternative for certain groups.

This study has several limitations. First, we had a small sample size reflective of the qualitative nature of the other component of this body of work. Due to the small sample size and the demographics of participants, results must be interpreted with caution and cannot be generalized to the broader population of Muslim immigrant women in our setting. Future research will need to be conducted on a larger scale, will need to include a diversity of ages and ethnicities, 
and will need to allow women to trial self-sampling devices to further assess acceptability and feasibility. Second, our results may have been affected by self-report and social desirability biases, including around reported screening status. Third, we were not able to allow women to try HPV self-sampling to provide more detailed feedback about acceptability, but as noted, planned future research will address this limitation.

\section{Conclusion}

Although HPV self-sampling has been studied in a variety of other populations, this body of work ${ }^{28}$ is the first that we know of to examine the acceptability of this method among Muslim immigrant women in Canada. This study adds important information to the literature related to promoting cancer screening among women under or never screened for cervical cancer. The results demonstrated that HPV self-sampling may provide a favorable alternative model of care to the traditional provider administered Pap testing. It has the potential to increase participation in cervical cancer screening. Potential benefits from HPV self-sampling may include removing several major barriers identified in the literature, such as modesty, access to female physicians, lack of transportation, and inconvenient hours of service. Future larger-scale research is required to allow women of a broad range of ages and ethnicities to trial devices to further explore acceptability and feasibility.

\section{Acknowledgments}

This study was funded by the Partnership for Change: The RBC Immigrant, Diversity and Inclusion Project Research Grant. The opinions, results, and conclusions reported in this article are those of the authors and are independent from the funding sources. Dr Aisha K Lofters is supported by the Canadian Cancer Society Research Institute Career Development Award in Cancer Prevention and as a Clinician Scientist by the University of Toronto Department of Family \& Community Medicine.

The dataset supporting the conclusions of this article is not publicly available, as we did not receive ethical approval for its publication, due to the small number of participants. Anyone who wishes to see the original data is invited to contact the authors.

\section{Author contributions}

AKL contributed to the conception of the study and to drafting and revising the article and gave final approval of the version to be published. MV contributed to the conception of the study, provided advice and direction for the study design and data interpretation, revised the article critically for important intellectual content, and gave final approval of the version to be published. MF contributed to the conception of the study, provided advice and direction for the study design and data interpretation, revised the article critically for important intellectual content, and gave final approval of the version to be published. AR contributed to the conception of the study, provided advice and direction for the study design and data interpretation, revised the article critically for important intellectual content, and gave final approval of the version to be published. All authors contributed toward data analysis, drafting and critically revising the paper and agree to be accountable for all aspects of the work.

\section{Disclosure}

The authors report no conflicts of interest in this work.

\section{References}

1. Jemal A, Bray F, Center MM, Ferlay J, Ward E, Forman D. Global statistics. CA Cancer J Clin. 2011;61(2):69-90.

2. Parkin DM, Bray F, Ferlay J, Pisani P. Global cancer statistics, 2002. CA Cancer J Clin. 2005;55(2):74-108.

3. World Health Organization [webpage on the Internet]. Estimated Cervical Cancer Incidence and Mortality Worldwide in 2012. 2014. Available from: http://globocan.iarc.fr/Pages/fact_sheets_cancer.aspx. Accessed April 18, 2017.

4. Boyle P, Levin B. World Cancer Report. Lyon, France: IARC Press; 2008.

5. Logan L, McIIfatrick S. Exploring women's knowledge, experiences and perceptions of cervical cancer screening in an area of social deprivation. Eur J Cancer Care. 2011;20(6):720-727.

6. Lofters A, Hwang S, Moineddin R, Glazier RH. Cervical cancer screening among urban immigrants by region of origin: a population-based cohort study. Prev Med. 2010;51(6):509-516.

7. Vahabi M, Lofters A, Kumar M, Glazier R. Breast cancer screening disparities among immigrant women by world region of origin: a population-based study in Ontario, Canada. Cancer Med. 2016;5(7):1670-1686.

8. Vahabi M, Lofters A, Glazier R. Breast cancer screening disparities in Ontario, Canada. BMC Public Health. 2015; 15:679-691. doi: 10.1186/ s12889-015-2050-5.

9. Statistics Canada [webpage on the Internet]. 2011 National Household Survey: Data Tables: Statistics Canada. 2013. Available from: http:// www12.statcan.gc.ca/nhs-enm/2011/dp-pd/dt-td/Lp-eng.cfm?LAN $\mathrm{G}=\mathrm{E} \& \mathrm{APATH}=3 \& \mathrm{DETAIL}=0 \& \mathrm{DIM}=0 \& \mathrm{FL}=\mathrm{A} \& \mathrm{FREE}=0 \& \mathrm{GC}=0 \&$ $\mathrm{GID}=0 \& \mathrm{GK}=0 \& \mathrm{GRP}=1 \& \mathrm{PID}=0 \& \mathrm{PRID}=0 \& \mathrm{PTYPE}=105277 \& \mathrm{~S}=0$ $\&$ SHOWALL $=0 \&$ SUB $=0 \&$ Temporal $=2013 \&$ THEME $=95 \&$ VID $=0$ \&VNAMEE=\&VNAMEF. Accessed April 18, 2017.

10. Racey S, Withrow DR, Gesink D. Self-collected HPV testing improves participation in cervical cancer screening: a systemic review and metaanalysis. Can J Public Health. 2013;104(2):e159-e166.

11. Saslaw D, Solomon D, Lawson HW, et al. American Cancer Society, American Society for Colposcopy and Cervical Pathology, and American for Clinical Pathology Screening guidelines for the prevention and early detection of cervical cancer. Am J Pathol. 2012;137(4): 516-542.

12. Petignant $P$, Vassilakos $P$. Is it time to introduce HPV self-sampling for primary cervical cancer screening? J Natl Cancer Inst. 2012;104(3): 166-167.

13. Agorastos T, Sotiriadis A, Chatzigeorgiou K. Can HPV testing replace the Pap smear? Ann N Y Acad Sci. 2010;1205:51-56. 
14. Bhatla N, Dar L, Patro AR, et al. Can human papilliomavirus DNA testing of self-collected vaginal samples compares with physiciancollected cervical samples and cytology for cervical cancer screening in developing countries? Cancer Epidemiol. 2009;33(6):446-450.

15. Ogilvie G, Krajden M, Maginley J, et al. Feasibility of self-collected of specimens for human papillomavirus testing in hard to reach women. Can Med Assoc J. 2007;177(5):480-483.

16. Mitchelle S, Ogilvie G, Steinberg M, Sekikubo M, Biryabarema C, Money D. Assessing women's willingness to collect their own cervical samples for HPV testing as part of ASPIRE cervical cancer screening project in Uganda. Int J Gynaecol Obstet. 2011;114(2):111-115.

17. Ogilvie G, Partrick DM, Schulzer M, et al. Diagnostic accuracy of self-collected vaginal specimens for human papillomavirus testing compared to clinician collected human papillomavirus specimens: a meta-analysis. Sex Transm Infect. 2005;81(3):207-212.

18. Zhao FH, Lewkowitz AK, Chen F, et al. Pooled analysis of a selfsampling HPV DNA test as a cervical cancer primary screening method. J Natl Cancer Inst. 2012;104(3):178-188.

19. Virtanen A, Nieminen P, Lustarinen T, Anttila A. Self-sample HPV tests as an intervention for non-attendees of cervical cancer screening in Finland: a randomized trial. Cancer Epidemiol Biomarkers Prev. 2011;20(9):1960-1969.

20. Virtanen A, Anttila A, Lustarinen T, Nieminen P. Self-sampling versus reminder letter: effects on cervical cancer screening attendance and coverage in Finland. Int J Cancer. 2011;128(11):2681-2687.

21. Schiffman M, Wentzensen N, Wacholders S, Kinney W, Gage JC, Castle PE. Human papilliomavirus testing in the prevention of cervical cancer. J Natl Cancer Inst. 2011;103(5):368-383.

22. Wright TC. Cervical cancer screening in the 21 st century: is it time to retire the Pap smear? Clin Obstet Gynecol. 2007;50(2):313-323.

23. Wallerstein N. Powerlessness, empowerment and health: Implications for health promotion programs. Am J Health Promot. 1992;6(3):197-205.

24. Labonté R, Laverack G. Health Promotion in Action: From Local to Global Empowerment. UK: Palgrave Mcmillian; 2008.

25. Chaskin RJ, Brown P, Venkatesh S, Vidal A. Building Community Capacity. New York: Aldine de Gruyter; 2001.

26. WHO. Milestones in Health Promotion: Statements from Global Conferences. 2009. Available from: http:/www.who.int/healthpromotion/ Milestones_Health_Promotion_05022010.pdf.Accessed April 18, 2017.

27. Marmot M, Friel S, Bell R, Houweling TA, Taylor S. Closing the gap in a generation: health equity through action on the social determinants of health. Lancet. 2008;372(9650):1661.

28. Vahabi M, Lofters A. Muslim immigrant women's views on cervical cancer screening and HPV self-sampling in Ontario, Canada. BMC Public Health. 2016;16(1):868.

29. Cancer Care Ontario [webpage on the Internet]. Cervical Cancer Screening Guidelines. 2014. Available from: https://www.cancercare. on.ca/pcs/screening/cervscreening/screening_guidelines/. Accessed April 18, 2017.
30. Ali-Risasi C, Mulumba P, Verdonck K, Broeck D, Praet M. Knowledge, attitude and practice about cancer of the uterine cervix among women living in Kinshasa, the Democratic Republic of Congo. BMC Womens Health. 2014;14:30.

31. Khosravi M, Shafaei S, Rajabzadeh A, et al. Validity and reliability of the knowledge, attitude and practice (KAP) questionnaire about cervical cancer and its screening among Iranian women. Basic Clin Cancer Res. 2012;4(1-2):1-6.

32. Padela AI, Peek M, Johnson-Agbakwu CE, Hosseinian Z, Curlin F. Associations between religion-related factors and cervical cancer screening among Muslims in greater Chicago. J Low Genit Tract Dis. 2014;18(4):326-332.

33. Johnson CE, Mues KE, Mayne SL, Kiblawi AN. Cervical cancer screening among immigrant and ethnic minorities: a systemic review using the health belief model. J Low Genit Tract Dis. 2008;12(3): $232-241$.

34. Matin M, LeBaron S. Attitudes toward cervical cancer screening among Muslim women: a pilot study. Women Health . 2004;29(3):63-77.

35. Redwood-Campbell L, Fowler N, Laryea S, Howard M, Kaczorowski J. "Before you teach me, I cannot know": immigrant women's barriers and enablers with regard to cervical cancer screening among different ethnolinguistic groups in Canada. Can J Public Health. 2011;102(3): 230-234.

36. Salmon KF. Health beliefs and practices related to cancer screening among Arab Muslim women in an urban community. Health Care Women Int. 2012;33(1):45-74.

37. Urquia M, O'Campo PJ, Heaman MI. Revisiting the immigrant paradox in reproductive health: the roles of duration of residence and ethnicity. Soc Sci Med. 2012;74(10):1610-1621.

38. Salehi R, Hynie M, Flicker S. Factors associated with access to sexual health services among teens in Toronto: does immigration matter? J Immigr Minor Health. 2014;16(4):638-645.

39. Causarano N, Pole JD, Flicker S. Adolescents, religion and sexual health knowledge gaps in Toronto. Can J Hum Sex. 2010;19(4):169-184.

40. Wray A, Ussher J, Perz J. Constructions and experiences of sexual health among young, heterosexual, unmarried Muslim women immigrants in Australia. Cult Health Sex. 2014;16(1):76-89.

41. Lofters A, Vahabi M, Glazier RH. The validity of self-reported cancer screening history and the role of social disadvantage in Ontario, Canada. BMC Public Health. 2015;15:28-38.

42. Burggess DJ, Powell AA, Griffin JM, Pattin MR. Race and validity of self-reported cancer screening behaviours: development of conceptual model. Prev Med. 2009;48(2):99-107.

43. Rauscher GH, Johnson TP, Cho YI, Walk JA. Accuracy of self-reported cancer screening histories: a meta-analysis. Cancer Epidemiol Biomarkers Prev. 2008;17(4):748-757.
Cancer Management and Research

\section{Publish your work in this journal}

Cancer Management and Research is an international, peer-reviewed open access journal focusing on cancer research and the optimal use of preventative and integrated treatment interventions to achieve improved outcomes, enhanced survival and quality of life for the cancer patient. The manuscript management system is completely online and includes

\section{Dovepress}

a very quick and fair peer-review system, which is all easy to use. Visit http://www.dovepress.com/testimonials.php to read real quotes from published authors. 